\title{
Makna Pluralisme Agama dan Relevansinya dalam Tradisi Sufi;Kajian atas Kepribadian Abu Mansur al-Halaj
}

\author{
Jarman Arroisi, ${ }^{1}$ Novita Sari ${ }^{2 *}$ \\ 1,2 University of Darusslam Gontor, Indonesia \\ Inovitasarimmq7@gmail.com, ${ }^{2}$ jarman@unida.gontor.ac.id \\ *Correspondence Author
}

\begin{abstract}
The study of wihhdtul adyan thoughts which is often identified with religious pluralism has recently attracted the attention of academics, researchers, and reviewers of religions. The issue of wihdatul adyan, by some parties forcibly tried to be juxtaposed and equated with the wihdatul wujud thought conceptualized by a Sufi figure such as al-Hallaj. This paper intends to examine the model and practice of Sufism in the person of Abu Mansur Al-Hallaj, who is referred to by some as the bearer of the idea of religious pluralism. This paper is also qualitative research with a philosophical-theological approach and concludes that; First, Al-Hallaj is not the originator and bearer of the idea of religious pluralism in Islam, this is supported by several opinions of Sufis about Al-Hallaj. Second, Al-Hallaj acknowledged that there are differences in religion, not equality of religions (read: all religions are true) because in his childhood he experienced religious diversity in his family environment. Third, the claim against Al-Hallaj as the originator or father of religious pluralism is an excessive and irresponsible title, because what Al-Hallaj did is not under the alleged claim. This study provides an understanding that wihdatul wujud which is identical to the person of Al-Hallaj is not the meaning of wihdatul adyan which is often referred to as religious pluralism as claimed by some academics.
\end{abstract}

Keywords: wahdat adyan, religious pluralism, Al-Hallaj

\begin{abstract}
Abstrak
Kajian pemikiran wihhdtul adyan yang sering diidentikkan dengan pluralisme agama belakangan menarik perhatian kalangan akademisi, peneliti dan para pengkaji agamaagama. Isu wihdatul adyan, oleh sebagian pihak secara paksa dicoba untuk disandingkan dan disamakan dengan pemikiran wihdatul wujud yang dikonsepsikan tokoh sufi seperti al-Hallaj. Tulisan ini bermaksud mengkaji model dan praktik tasawuf dalam pribadi Abu Mansur Al-Hallaj yang disebut oleh sebagian pihak sebagai pengusung ide pluralisme agama. Tulisan ini juga merupakan penelitian kualitatif dengan pendekatan filosofis-teologis dan berkesimpulan bahwa; Pertama, Al-Hallaj bukanlah pencetus dan pengusung ide pluralisme agama dalam Islam, hal ini didukung dari beberapa pendapat para sufi tentang Al-Hallaj. Kedua, Al-Hallaj mengakui adanya perbedaan agama bukan kesetaraan agama-agama (baca: semua agama benar), sebab di masa kecilnya sudah mengalami keberagaman agama dalam lingkungan keluarganya. Ketiga, klaim terhadap Al-Hallaj sebagai pencetus atau bapak pluralisme agama adalah sebutan yang berlebihan dan tidak bertanggungjawab, karena apa yang dilakukan Al-Hallaj tidak sesuai dengan klaim yang dituduhkan itu. Kajian ini memberikan pemahaman bahwa wihdatul wujud yang identik dengan pribadi Al-Hallaj sejatinya bukanlah makna wihdatul adyan yang sering disebut sebagai paham pluralisme agama seperti yang diklaim sebagian akademisi.
\end{abstract}

Kata kunci: wahdat ad-dyan, pluralisme agama, Al-Hallaj 


\section{Pendahuluan}

Perbincangan mengenai titik temu agama-agama merupakan pembahasan yang menarik untuk dibahas. Banyak asumsi yang menyatakan bahwa setiap agama memiliki Tuhan yang sama hanya penyembahan secara ritual saja yang berbeda, ideologi ini disebut pluralisme agama. Para penggasan ideologi ini menyatakan bahwa adanya idelogi ini muncul dengan tujuan perdamaian yang berdasarkan kepada keyakinan universal, sehingga tidak ada lagi konflik umat beragama karena setiap agama menyembah Tuhan yang sama. ${ }^{1}$ Bahkan ada beberapa peneliti yang menyatakan bahwa asal-usul ideologi pluralisme Agama beasal dari ajaran Islam, ${ }^{2}$ tepatnya dalam dimensi tasawuf ${ }^{3}$.

Dengan demikian, kajian kritis mengenai isu-isu pluralisme yang dikaitan dengan kajian tasawuf perlu untuk dikaji secara mendalam, agar tidak tejadinya dekonstruksi terhadap kalangan sufi. Penelitian ini juga memiliki relevansi dengan penelitian terdahulu diantaranya; Pertama, penelitian Kholod Karomi, Penolakan Ibnu Arabi terhdapa Pluralisme Agama, "hasil penelitian menunjukan bahwa Ibnu Arabi diklaim sebagai salah tokoh sufi yang mengusung konsep wahdat al-adyan, padahal makna wahdat al-adyan yang dipahami oleh para sufi yang sahih sebenarnya bukan dalam konteks agama tapi dalam konteks tingkatan wujud, dimana Allah dipahami sebagai wujud akhir yang Absolut (al-Wujud al-Akhir al-Mutlaq). ${ }^{4}$ Kedua, penelitian Abdullah Muslich Rizal Maulana, Kesatuan Transenden Agama-Agama dalam Perspektif Tasawuf (Kritik atas Pemikiran Frithjof Shoun), hasil penelitian ini menyatakan bahwa Frithjof Shoun merupakan tokoh yang menjadi penggas kesatuan transenden agama-agama yang disandarkan kepada sufi, dan menghasilkan relasi yang sangat kuat terhadap berkembangnya pluralisme agama yang bersifat modern. ${ }^{5}$ Ketiga, penelitian Mawardi, Tasawuf dan Pluralitas dalam Al-Qur'an, hasil penelitian ini menyimpulkan bahwa banyaknya tokoh pluralis yang menyandarkan pemahaman pluralisme agama pada sufi, padahal pengakuan terhadap pluralisme agama oleh sufi

\footnotetext{
${ }^{1}$ Firdaus M. Yunus, “Agama Dan Pluralisme,” Jurnal Ilmiah Islam Futura 13, no. 2 (2014): 213, https://doi.org/10.22373/jiif.v13i2.72.

2Umi Hanik, "Pluralisme Agama Di Indonesia," Jurnal Pemikiran Keislaman 25, no. 1 (2014): 44-63, https://doi.org/10.33367/tribakti.v25i1.154.

${ }^{3}$ Ilham Masykuri Hamdie, "Jejak-Jejak Pluralisme Agama Dalam Sufisme," Khazanah: Jurnal Studi Islam Dan Humaniora 17, no. 2 (2019): 263, https://doi.org/10.18592/khazanah.v17i2.3207.

${ }^{4}$ Kholid Karomi, "Penolakan Ibnu Arabi Terhadap Pluralisme Agama," Kalimah 12, no. 1 (2014): 49, https://doi.org/10.21111/klm.v12i1.218.

${ }^{5}$ Abdullah Muslich Rizal Maulana, "Kesatuan Transenden Agama-Agama Dalam Perspektif Tasawuf (Kritik Atas Pemikiran Frithjof Schuon)," Kalimah 12, no. 2 (2014): 197, https://doi.org/10.21111/klm.v12i2.236. 
tidak diakui dan tidak ada dalam tradisi sufi.Dari semua penelitian terdahulu dalam tulisan ini memiliki persamaan dan perbedaan, dari aspek persamaannya penelitian terdahahulu dan tulisan ini sama-sama memfokuskan pada kajian ktirik tokoh sufi yang banyak di jadikan oleh para pluraris untuk mendapatkan legitimasi bahwa pemahaman pluralisme agama itu berasal dari Islam. Sedangkan dari perbedaanya penelitian terdahulu belum ada yang membahas tokog sufi al-Hallaj dan dalam tulisan ini akan dibahas lebih fokus dan komprehensif dalam pemikiran al-Hallaj.

Oleh karena itu adanya tulisan ini bertujuan untuk memberikan penjelasan mengenai pemikiran Pluralisme agama itu bukan berasal dari Islam apalagi disebut berasal dari dimensi tasawuf. Bahkan di Indonesia sudah menyatakan bahwa pemahaman mengenai pluralisme agama di larang, dengan pernyataan bahwa pluralisme agama adalah suatu paham yang mengajarkan bahwa semua agama adalah sama dengan karenanya kebenaran setiap agama adalah relatif ${ }^{6}$. Hal ini berlandaskan pada fatwa MUI dalam Musyawarah Nasional VII pada 2005. ${ }^{7}$

Maka dalam kajian ini, penulis mencoba melakukan analisa lebih dalam mengenai kaitannya pluralisme agama dengan tasawuf. Dalam hal ini ada salah satu tokoh sufi yang terkenal pada abad ke-9. Yang memberikan wawasan dalam khazanan tawasuf Islam mengenai kecintaan seorang hamba kepada Tuhannya.Ia terkenal dengan pernyataannya yakni “Ana Al-Haqq" (Aku lah kebenaran) yang mengantar ia sebagai sufi yang kontroversial, dia adalah Al-Hallaj.Yang kemudian di klaim oleh kalangan pluralis sebagai bapak pluralisme agama dalam Islam sekaligus pencetus konsep yang disebut dengan konsep wahdat Al-Adyan. Oleh karena itu, dengan adanya tulisan ini penulis memberikan dua hipotesis awal mengenai pemikiran al-Hallaj dalam konsep wahdat al-Adyan, Pertama; Al-Hallaj memang memiliki konsep wahdat Al-Adyan, namun dimaknai berbeda oleh para pluralis, kedua; Al-Hallaj tidak sama sekali memiliki konsep wahdat Al-Adyan.

\section{Metode}

Dalam tulisan ini peneliti menggunakan metode penelitian kualitatif dengan pendekatan filosofis-teologis. ${ }^{8}$ Metode ini digunakan untuk mencari makna dan yang

${ }^{6}$ MUI, "Fatwa MUI Tentang Pluralisme, Liberalisme Dan Sekularisme Agama," 1970, 98-100.

${ }^{7}$ Majelis Ulama Indonesia, "Pluralisme, Liberalisme, Dan Sekularisme Agama," Himpunan Fatwa MUI, 2005, 96.

${ }^{8}$ Siti Zulaiha, "Pendekatan Metodologis Dan Teologis Bagi Pengembangan Dan Peningkatan Kualitas Guru MI," Ar-Riayah : Jurnal Pendidikan Dasar 1, no. 01 (2017):p. 45-64.

Tribakti: Jurnal Pemikiran Keislaman

Volume 32, Nomor 1, Januari 2021 
berkaitan dengan dengan hal-hal berikut: 1. Sesuatu yang bersifat metafisik, yang tidak dapat dilihat oleh mata kepala manusia; 2. Alam semesta yang fisikal dan terbentuk oleh hukum perubahan; 3. Sesuatu yang rasional dan irasional; 4. Semua yang bersifat natural ataupun supranatural; 5. Akal, rasa, pikiran, intuisi, dan persepsi; 6. Hakikat yang terbatas dan yang tidak terbatas; 7. Teori pengetahuan pada semua keberadaan pengetahuan manusia yang objektif ataupun subjektif; 8. Fungsi dan manfaat segala sesuatu yang didambakan manusia atau dihindarinya; 9. Kebenaran spekulatif yang bersifat rasional tanpa batas sehingga berlaku pemahaman dialektis terhadap berbagai penemuan hasil pemikiran manusia. Tesis yang melahirkan antitesis dan terciptanya sintesis. ${ }^{9}$ Kemudian ditambah dengan teologi sebagai kritik agama berarti antara lain mengungkapkan berbagai kecenderungan dalam institusi agama yang menghambat panggilannya; menyelamatkan manusia dan kemanusiaan. ${ }^{10}$ Metode ini digunakan oleh peneliti untuk menjelaskan konsep wahdatul adyan al-Hallaj secara cermat dalam bentuk dan pernyataan rumusan-rumusan pendapat. ${ }^{11}$ Dalam penelitian kualitatif, analisis muatan lebih dekat dengan analisis wacana yang lebih dimaksudkan sebagai metode analisis data dan bahkan lebih kepada metode tafsir teks. ${ }^{12}$ Artinya dalam analisis data pada hakikatnya peneliti memberikan penafsiran terhadap gagasan primer dan dikonfrontasikan dengan gagasan primer lainnya atau gagasan sekunder.

Dengan menggunakan pendekatan analisis filosofis-teologisini penulis berusaha mengkaji konsep wahdat al-adyan al-Hallaj dilihat dari kajian tasawuf. Penelitian ini juga tergolong dalam penelitian kepustakaan (library research). Ini karena kajian dan analisis dalam penelitian ini bersumber dari kepustakaan seperti buku, jurnal, artikel, majalah, dan sumber pustaka lainnya yang bersifat hardfile maupun softfile. Dalam konteks penelitian, kajian kepustakaan adalah upaya mencari dan menghimpun bahan dari sumber buku, hasil penelitian dan sebagainya yang terkait dengan konsep wahdat al-Adyan al-Hallaj, baik dalam bentuk penjelasan aspek fokus penelitian, maupun untuk mempertegas posisi penelitian yang akan dilakukan. ${ }^{13}$

\footnotetext{
${ }^{9}$ Beni Ahmad Saebani, Filsafat Ilmu Dan Metode Penelitian (Bandung: Pustaka Setia, 2015), 27.

${ }^{10}$ Abuddin Nata, Metodologi Studi Islam (Jakarta: Raja Wali Press, 2013), 31.

${ }^{11}$ Achmad Slamet, Buku Ajar Metodologi Studi Islam: (Kajian Metode Dalam Ilmu Keislaman) (Yogyakarta: Deepublish, 2016), 41.

12 Mudjia Rahardjo, Analisis Muatan Sebagai Metode Pengukuran Kata Pengantar Dalam Nanang Martono, "Metode Penelitian Kualitatif Analisis Isi Dan Analisis Data Sekunder (Jakarta: PT Raja Gravindo Persada, 2014), i.

${ }^{13}$ Ibrahim, Metodologi Penelitian Kualitatif (Bandung: ALFABETA, 2015), 37.
} 
Teknik pengumpulan data yang digunakan adalah pengumpulan dokumentasi dari data primer dan sekunder. Karena karya al-Hallaj banyak dibakar oleh pemerintah pada masanya maka buku primer yang dijadikan rujukan adalah Al-Hallaj, Husain bin Manshur. 2009. Al-Thowasin Terj. Kasyif Ghoiby, Yogyakarta: Titah Surga. Didukung dengan buku Louis Massignon sebagai peneliti yang fokus mengkaji tentang manuskripmanuskrip al-Hallaj diantaranya ; Louis Massignon “Al-Hallâj”, M. M. Sharif (1963), A History of Muslim Philosophy, volume one, Wiesbaden: Otto Harrassowitz, .Al-Hallaj Sang Sufi Syahid, Yogykarta, Fajar Pustka Baru, 2000, Al-Hallaj, Mystic and Martyr Abridged Edition, Princeton Universitu Press, New Jersey. The Passion of Al-Hallaj: Mystic and Martyr of Islam Abridged Edition Princeton University Press, New Jersey. Le Diwan AL-Hallaj. Essay De Reconstitution, Edition Et Traduction, Jurnal Asiatuque, Librairie Orinetaliste Paul Geuthner, Janver, Mars, 1931. diterjemah dari Le Diwan ALHallaj. Essay De reconstitution, Edition Et Traduction, oleh Louis Massignon. Dalam penelitian ini data sekunder didapat dari buku atau jurnal-jurnal ilmiah yang berkaitan dengan pembahasan kajian ini.

\section{Hasil dan Pembahasan}

\section{Metafisika Al-Hallaj Dalam Tasawuf}

Dari peneltian yang dilakukan dalam kajian wahdatul adyan perspektif al-Hallaj, mendapatkan hasil berupa; pertama al-Hallaj itu merupakan tokoh sufi yang sering disandarkan bahwa ia adalah bapak pluralisme agama, padahal jika dianalisa secara mendalam al-Hallaj tidak memberikan pernyatan secara nyata bahwa ia mendukung pemahaman kesatuan agama-kesatuan agama tetapi lebih mengarah kepada wihdatul wujud dalam hal ini Allah sebagai wujud akhir yang absolut serta al-Hallaj tidak memberikan statement tentang kesetaraan agama atau semua agama sama tetapi justru al-Hallaj memberikan penjelasan mengenai keberagaman agama, hal ini dilatar belakangi oleh hidup al-Hallaj yang dibesarkan dari pluralitas agama yang berbeda dalam lingkungan keluarganya. Oleh karena itu untuk memahami konsep al-Hallaj alangkah baiknya di mulai dari memahami biografi al-Hallaj.

Al-Hallaj merupakan seorang mistik, penyair, dan guru tasawuf di Persia. Dalam kategori nama lengkap al-Hallaj memiiki dua versi nama, yang pertama Abu Al-Mugit 
Husain ibn Mansur al-Hallaj ${ }^{14}$ dan yang kedua Abu al-Mughits al-Husain ibn Mansur ibn Muhammad al-Baidhawi. ${ }^{15}$ Dari kedua versi nama ini, nama yang paling sering disebutkan adalah Abu Al-Mugit Husain ibn Mansur al-Hallaj, sedangkan nama asli dari Al-Hallaj adalah versi kedua, yakni Abu al-Mughits al-Husain ibn Mansur ibn Muhammad al-Baidhawi. Al-Hallaj lahir pada 244 H (858 M) di Thur, sebuah kampung dekat Baidha, sebelah timur laut Syiraz, termasuk provinsi Fars (sebelah Barat Daya Iran sekarang). Al-Hallaj adalah keturunan Persia, kakeknya (Muhammad) adalah penganut ajaran Zoroaster (Majusi) sedangkan ayahnya adalah Muslim. ${ }^{16}$

Al-Hallaj sejak kecil dididik dengan nilai-nilai Islami, bahkan ketika berusia 12 tahun dia selesai belajar al-Qur'an dan hafal di luar kepala yang diperoleh dari lingkungan para Qurra' al-Qur'ân madzhab Hanbali. Lebih lanjut lagi dalam proses perjalanan hidupnya Al-Hallaj belajar dengan para sufi. Diantaranya ada beberapa nama guru Al-Hallaj yang memberikan pengaruh dalam pemikirannya yakni, Sahl ibn Abdillah al-Tustarari (w.203), merupakan seorang sufi dan mufassir terkemuka dengan landasan tasawuf yang mengamalkan hasil penafsirannya dengan amaliyah sufiyyah secara ketat dan keras. ${ }^{17}$ Dari al-Tustari inilah al-Hallaj belajar dengan teori Nur Muhammad (the Light of Muhammad) yang kemudian berpengaruh besar dalam pemikiran tasawufnya. ${ }^{18}$ Al-Hallaj juga belajar belajar kepada 'Amir Makki (w. 297/909) yang lebih dikenal dengan nama Abu Thalib al-Makki penulis Quth al-Qulub, salah seorang murid Junaid al-Bagdhad. ${ }^{19}$ Kemudian Al-Hallaj juga belajar kepada Nuri al-Baghawi (w.225-295) ${ }^{20}$ Belajar dengan Nuri, Al-Hallaj mendapatkan konsep tentang cinta murni (mahabbah), kesungguhan cinta keimanan yang diwujudkan dalam ibadah serta konsep hulul yakni Tuhan dalam jiwa manusia yang bercahaya. ${ }^{21}$

Dari proses belajar itulah Al-Hallaj tumbuh dan berkembang sebagai seorang sufi dan menulis beberapa buku yang di dalamnya tertuang mengenai pemikiran

\footnotetext{
${ }^{14}$ Internasional Jurnal of Islamic Thought, "Martyrdom of Al-Hallaj and Unity of the Existence: The Condomners and the Commenders," n.d., 106..

${ }^{15}$ Penyebutan nama Baidhawi merupakan penamaan yang berasalkan dari daerah Al-Hallaj di lahirkan. Lihat: Louis Massignon, A History of Muslim Philosophy (Wiesbaden: Otto Harrassowitz, 1963).

${ }^{16}$ Herbert W. Mason, Al-Hallaj (London: Curzon Press, 1995), 1.

${ }^{17}$ Reynold A. Nicholson, Al-Hallaj, Encyclopedia of Religion and Ethics (New York: Charles Scribners Son, tt, n.d.), 481.

${ }^{18}$ Nicholson, 100.

${ }^{19}$ Mason, Al-Hallaj, 3.

${ }^{20}$ Louis Massignon, Al-Hallaj, Mystic and Martyr (Abridged Edition, Princeton Universitu Press, New Jersey, n.d.). buku ini juga tersedia dalam bahasa Indonesia dengan judul Al-Hallaj Sang Sufi Syahid (Yogykarta: Fajar Pustka Baru, 2000).

${ }^{21}$ Massignon, Al-Hallaj, Mystic and Martyr, 79.
} 
kesufiannya, karya al-Hallaj yang diketahui masih bertahan sampai saat ini hanya dua yakni al-Thawasin dan Diwan al-Hallaj. ${ }^{22}$ Kitab Al-Thawasin merupakan salah satu karya dari Al Hallaj yang di dalamnya kita bisa memahami bentuk dari kesufian AlHallaj. Di dalamnya membahas tentang sebelas prosa-prosa yang menerangkan tentang bentuk kesufian Hallaj. Pada dasarnya pemikiran Al-Hallaj telah tercurahkan di dalam bukunya Al-thawasin yang terbentuk di dalam suatu kesatuan Prosa. Yang berisikan tiga hal yang penting tentaang ajaran Al-Hallaj yaitu, ${ }^{23}$ hulul ketuhanan menjelma kedalam diri insan (nasut), Al-Haqiqah al-muhamadiyah (Nur Muhammad), dan wahdat al Adyan (kesatuan agama-agama). Namun, dalam hal ini pernyataan mengenai konsepkonsep pemikiran Al-Hallaj terutama konsep wahdat al Adyan (kesatuan agamaagama), perlu di kaji lagi secara mendalam.

Selain al-Thawasin Al-Hallaj juga menulis buku dengan judul Diwan Al-Hallaj, berisi kumpulan cuplikan puisi atau qasidah-qasidah yang berhasil dihimpun dari berbagai orang dan pengikutnya dari berbagai sumber. ${ }^{24}$ Karya-karya Al-Hallaj merupakan luapan perasaan mengenai pengalaman mistis yang ia rasakan, kemudian di tulis dalam baris-baris puisi. Salah satu pengalaman mistis yang ia rasakan ialah, ketika sang Kekasih (Tuhan) lalu merasuk ke dalam dan menepati hatinya, proses penyatuan ini disebut dengan hulul. ${ }^{25} \mathrm{Hal}$ ini kemudian menjadikan Al-hallaj dikenal sebagai tokoh sufi yang kontroversial dijamannya. Bahkan ada beberapa kalangan yang mengangap ia sebagai sufi yang sesat, karena ia dianggap merusak tatanan aqidah umat muslim karena konsep hulul yang dia miliki dengan memberikan penyataan Ana AlHaqq (Aku adalah kebenaran). Pernyataan Ana Al-Haqq (Aku adalah kebenaran) inilah yang menghantarkan Al-Hallaj kepada hukuman mati. Hukuman yang harus ia terima ialah disalib, dan dihukum mati dikarenakan tuduhan kesesatan yang diberikan oleh pemerintah Abbasiyah yang dipimpin oleh khalifah Muqtadir.

Al-hallaj ditetapkan mendapat hukum mati dan di eksekusi pada selasa tanggal 26 Maret 922 M. Ketika ia disalib ia sempat menyampaikan ucapan,

"Mereka adalah hamba-hamba-Mu yang telah berkumpul untukmembunuhku disebabkan kefanatikan terhadap agama-Mu dan sebagai ibadah (pengabdian)

${ }^{22}$ Syeikh Husain Manshur, Hussain Manshur Al-hallaj, and Muhammad Saw, "At Tho wasin Al Azal," n.d., 12.

${ }^{23}$ Husain bin Manshur Al-Hallaj, Al-Thowasin, ed. Terj.Kasyif Ghoiby (Yogyakarta: Titah Surga, 2009), 13-19.

${ }^{24}$ Louis Massignon, "LE DIWAN AL-Hallaj. Essay De Reconstitution,” Jurnal Asiatuque, no. Librairie Orinetaliste Paul Geuthner (1931).

${ }^{25}$ M. Alfatih Suryadilaga, Miftahus Sufi (Yogyakarta: Teras, 2018), 170.

Tribakti: Jurnal Pemikiran Keislaman

Volume 32, Nomor 1, Januari 2021 
kepada-Mu.Maka berikan keampunan pada mereka.Jika engkau bukakan pada mereka apa yang telah engkau bukakan pada, niscaya mereka tidak akan melakukan apa yang telah mereka lakukan". ${ }^{26}$

Ada dua alasan besar yang dijadikan rumusan dalam memvonis hukum bagi alHallaj yakni alasan yang bersifat teologis dan politis. ${ }^{27}$ Al-Hallaj dihukum di tiang gantungan, setelah itu kaki dan tangannya dipotong, kepalanya dipenggal dan tubuhnya disiram dengan minyak lalu dibakar dan abunya dibawa ke menara di tepi sungai Tigris. $^{28}$ Proses perjalanan hidup al-Hallaj merupakan sebagian kecil dari simbol pencarian manusia terhadap suatu yang bersifat metafisika yang sebagian manusia tidak akan memperayainya jika pengalaman itu tidak dirasakan. Maka al-Hallaj hadir sebagai salah satu tokoh sufi yang mempublikasikan pengalaman spiritualnya. Dari perjalanan hidup al-Hallaj sebagai seorang sufi yang kontroversial ini banyak pendapat yang dilontarkan oleh para ulama atas dirinya.

\section{Pandangan Ulama terhadap Al-Hallaj}

Al-Hallaj merupakan seorang sufi terkenal, karena memberikan pernyataan Ana Al-Haqq (Aku adalah kebenaran). Dari pernyataannya ini banyak dari kalangan sufi bahkan ulama memberikan komentar terhadap dirinya. Dalam memberikan komentar terhadap al-Hallaj ini para ulama tersebut terbagi dalam tiga golongan; golongan pertama, golongan ini merupakan golongan yang kontra terhadap pemikiran tasawuf alHallaj; golongan kedua, pada golongan kedua ini ada beberapa ulama yang ditanya mengenai Al-Hallaj tetapi tidak memberikan keputusan apakah setuju atau tidak dengan pengamalan tasawuf Al-Hallaj; golongan ketiga, golongan ini adalah golongan yang pro atau mendukung bahkan memberikan pujian terhadap Al-Hallaj

Golongan pertama, ialah golongan yang menolak pemikiran tasawuf al hallaj, karena al-Hallaj memiliki perbedaan yang signifikan dalam pengamalan tasawufnya, maka seorang ulama Zahiri yakni Abu Daud al-Isfahani mengeluarkan fatwa yang menyatakan bahwa al-Hallaj sesat. ${ }^{29}$ Ibnu Dawud menyatakan bahwa tafsiran Al-Qur'an

${ }^{26}$ Ibnu Khalkan, Wafayat Al-A'yaan, Juz I (Boolaq, n.d.), 184.

27 Mulyadi Kartanegara, "Eksekusi Al-Hallaj: Persoalan Teologi Atau Konspirasi Politik?" Dalam Sekapur Sirih Dalam Buku Gilani Kamran, Ana Al-Haqq (Akulah Kebenaran): Menyingkap Teosofi Al-Hallaj Dalam Kitab Thawasin, ed. Terj. Wahyudi (Surabaya: Risalah Gusti, n.d.), vii-xv lihat juga $15-18$.

${ }^{28}$ Lathiful Khuluq, The Notion of Love of God in Al Hallaj Dalam the Dynamic of Islamic Civilization (Yogyakarta: Titian Press, n.d.), 90.

29 Muhammad Sholikhin, Filsafat Dan Metafisika Dalam Islam "Sebuah Penjelajahan Nalar Pengalaman Mistik Dan Perjalananan Aliean Manunggaling Kawula-Gusti (Yogyakarta: NARASI, 2008), 209. 
yang disajikan oleh al-Hallaj ialah tafsiran yang berlawanan dengan Sunnah Nabi, dan berlawanan dengan pengertian bahasa Arab yang sudah baku dan jelas. ${ }^{30}$ Dalam kalangan sufi yang bermazhab Sunni Al-Qusyairi ${ }^{31}$ memiliki peranan dominan dalam penolakannya terhadap al-Hallaj, sehingga ketika pembahasan mengenai biografi 83 sufi dalam al-Risalahnya, Al-Qusyairi tidak mencantumkan nama al-Hallaj. ${ }^{32}$ Hal senada juga ddilakukan oleh al-Ghazali dalam ihyanya, al-Ghazali dengan satun menolak syatahat al-Hallaj dengan alasan bahwa ungkapan yang dilakukan oleh alHallaj itu memperdaya publik untuk sesuatu yang tidak bermanfaat, sehingga masyarakat meninggalkan aktivitas sehari-hari mereke karena tergoda akan cepat bertemu dengan Allah, tanpa melalui maqamat dan ahwal. ${ }^{33}$

Golongan kedua, Ibnu Surayj memberikan pernyataan mengenai al-Hallaj bahwa "Ilmuku tidak mendalam tentang dirinya, sehingga aku tidak akan mencoba melakukan evaluasi secara doktrinal terhadapa dirinya. ${ }^{34}$ Ibn Suraij juga menambahkan bahwa AlHallaj adalah tipe sempurna ulama Islam. Ia hafal Al-Qur'an dan syarat dengan pemahamannya, mengusai ilmu fiqih dan hadis serta memiliki kemampuan tinggi dan sempurna dalam tasawuf. Dan pribadinya hampir dihiasai dengan semua kesalehannya. ${ }^{35}$ Syaikh 'Abd al-Qadir al-Jailani memahami kebenaran esensial ajaran Mansur al-Hallaj, dengan berkata 'Husain al-Hallaj tealah membuat blunder yang serius, sampai-sampai tidak ada seorang pun yang mengulurkan tangan (untuk membantunya keluar dari blunder tersebut. Tetapi jika saja akau hidup sezaman dengannya, aku akan mengulurkan tanganku untuknya. Sebab siapun sari sahabarsahabatku, murid-muridku, teman-teman kekasaihku yang melewati gunung rintangan (sandungan) antara (semenjak) sekarang hingga hari kiamat, pasti akan (datang) di sana untuk mengulurkan tanganku. ${ }^{36}$

Golongan ketiga, ialah golongan yang setuju dengan pemikiran al-Hallaj, walaupun banyak cercaan dan hinaan yang didapatkan oleh Al-Hallaj ada beberapa

${ }^{30}$ Massignon, Al-Hallaj, Mystic and Martyr, 320.

${ }^{31}$ Nama lengkap Al-Qusyairi (376- w. 465) adalah Abu al-Qasim Abdul Karim bin Hawazin bin Abdul Malik bin Thalhah bin Muhammad al-Nisabury Al-Qusyairi al-Syafi'i. Sedangkan nama alQusyairu di belakang namanya sebagai penisbatan bahwa ia merupakan keturunan Kabilah Qusyair bin Ka'ab yang berasal dari Arab dan menempati Khurasan. Abd al-Halim Mahmud, Al-Risalah AlQusyairiyah (Kairo: Muassasah Dar al-Sya’b, 1989), 21.

${ }^{32}$ Kautsar Azhari Noer et Al, Warisan Agung Tasawuf: Mengenal Karya Besar Para Sufi (Jakarta: Sandra Press, 2015), 239.

33 Abdul Amir Al-A'sam, Al-Faylasuf Al-Ghazali, n.d., 140-42., Lihat juga : Abu Hamid AlGhazali, "Ihya Ulum Al-Din" (Kairo: Mushthafa al-Babi al-Halabi, 1939), 42.

${ }^{34}$ Al-Hallaj, Al-Thowasin, 21.

${ }^{35}$ Khalkan, Wafayat Al-A'yaan, Juz II, 42.

${ }^{36}$ Syekh Abdul Qadir Al-Jailani, Qalaid Al Jawahir, n.d., 89.

Tribakti: Jurnal Pemikiran Keislaman

Volume 32, Nomor 1, Januari 2021 
tokoh sufi yang membelanya di antaranya; Jalaluddin Rumi ${ }^{37}$, dan Faridudin Attar. Sarraj $^{38}$ membela al Hallaj karena ia seorang muslim. ia percaya bahwa akidah dan keyakinan al hallaj tidak dapat diragukan sama sekali sebagi seorang muslim. Al sarraj menurutkan bahwa kata-kata terakhir yang al-Hallaj ucapkan sesaat sebelum dihukum mati adalah, "Dialah Tuhan satu-satunya". 39 Ibn Aqil mengaggap al-Hallaj sebagai seorang wali dan tak pernah meragukan keikhlasan serta kesalehannya. Inn aljauzi mengambarkan bahwa ia punya salinan tulisan tangan dari risalah Ibn Aqil yang memuji al-Hallaj dengan juz fi al nashr karamat al hallaj (pujian terhadap karamah-karamah alHallaj). ${ }^{40}$

Dari semua pendapat tentang al-Hallaj baik yang mendukung maupun yang menolak pemikirannya, penulis mengambil kesimpulan bahwa al-Hallaj merupakan sufi yang memberikan kontribusi terhadap khazahan Islam. Al-Hallaj merupakan sufi yang menyiarkan pengalaman spiritual terhadap publik sehingga menimbulkan kontroversi. Dan bahkan para sufi terkemukan seperti Jalaluddin Rumi, Fariddudin Attar, dan Abu Nasr al-Sarraj membrikan pendapat positif kepada al-Hallaj.

\section{Al-Hallaj dan Pluralisme Agama}

Dalam konsep pemikirannya Al-Hallaj disebut sebagai bapak pluralisme agama.Al-Hallaj disebut sebagai pencetus pemikiran pluralisme agama dalam Islam. Kalangan pengusung pluralisme agama menyatakan bahwa dalam ajarannya al-Hallaj menyiarkan pemahaman pluralisme agama. Untuk itu dalam pemabahasan ini akan di bahas mulai dari definisi pluralisme agama dan klaim para pluralis yang menyatakan bahwa al-Hallaj merupakan bapak pluralisme agama. Dengan demikian dalam memahami konsep pluralisme agama yang harus dilakukan ialah dengan memahami definisi dari pluralisme agama.

Pluralisme agama merupakan padanan kata dari plural yang artinya jamak, lebih dari satu (more than one). ${ }^{41}$ Dari berbagai kamus pluralisme dapat disederhanakan ke dalam dua pengertian: pertama, pengakuan terhadap keragaman kelompok, baik yang bercorak ras, agama, suku, aliran, maupun partai dengan tetap, menjunjung tinggi

\footnotetext{
${ }^{37}$ Jalaludin Rumi, Fihi Ma Fihi (Yogyakarta: FORUM, 2014), 430.

38 Al-Hallaj, Al-Thowasin, 2-21.

39 Abu Nasr Al-Sarraj, Al-Luma, ed. Editor Abdul Halim Mahmud dan Thaha Abdul Baqi Suru (Kairo: Dar al-Kutub al-Haditsah, 1960), 378.

${ }^{40}$ Syekh Muhammad Hisyam Kabbani, Tasawuf Dan Ihsan "Antivirus Kebatilan Dan Kezaliman (Jakarta: PT. Serambi Ilmu Semesta, 2007), 115.

41 A.S Hornby, Oxford Advanced Leaner's Dictionary of Corrent English Language, Cet.11 (London: Oxford Univeristy Press, 1983), 889. 
aspek-aspek perbedaan yang sangat karakteristik diantara kelompok-kelompok tersebut. Pluralisme dalam pengertian pertama merupakan toleransi, dimana masing-masing agama, ras, suku dan agama berpegang pada prinsip masing-masing dan menghormati prinsip dan kepercayaan orang lain. ${ }^{42}$ Kedua, makna pluralisme berarti relatif yang berarti bahwa tidak ada pendapat yang benar atau semua pendapat adalah sama benarnya. ${ }^{43}$ Inti dari pluralisme agama adalah relativitas kebenaran pada setiap agama di dunia, sebagai bentuk toleransi untuk memelihara kerukunan hidup antarumat beragama di tengah-tengah keragaman yang ada. ${ }^{44}$

Asal usul pendapat pluralisme berawal dari klaim agama-agama Ibrahim a.s (The Abrahamic Faits) ${ }^{45}$ yang populer dalam studi agama-agama sebagai payung untuk agama Yahudi, Krisnten dan Islam. Term ini kemudian, oleh kaum pluralis, diwacanakan untuk membangun paradigma kesatuan agama-agama semitik. Sebenarnya, wacana pluralisme terkait dengan pemikiran Barat postmodern.Begitu kata Akbar S Ahmed dalam bukunya Postmodernism and Islam bahwa pada posmodernisme semangat nilai-nilai pemikiran Barat berupa pluralism sangat terlihat. ${ }^{46}$ Sudah jamak, doktrin primer posmodernisme adalah subyektifitas dan relatifitas kebenaran ${ }^{47}$ Posmodernisme merupakan sistim pemikiran yang anti agama serta memarginalkan Tuhan. Akarnya bisa dilacak menurut para filosof Barat pembuka gerbang posmo. Nietzche (1844-1900) ${ }^{48}$ misalnya, menggunakan jeritan kematian Tuhan mereduksi nilai kepercayaan yang selama ini dipercaya absolut, jeritan itu diistilahkan dengan nihilisme. Dengan pandangan ini kebenaran apapun termasuk agama adalah relatif. Dalam bukunya, Akbar S Ahmed pula menyebutkan bahwa posmodernisme selalu berakibat fundamentalisme (agama) sebagai musuh, dan untuk menghadapinya adalah dengan menebar pluralisme.

42 Hamid Fahmy Zarkasyi, Misykat Refleksi Tentang Westernisasi, Liberalisasi Dan Islam (Jakarta: INSISTS, 2012), 138.

43 Adib Fuadi Nuriz, Problem Pluralisme Agama Dan Dampaknya Terhadap Kehidupan Sosial Keagamaan (Ponorogo: CIOS, 2015), 1.

${ }^{44}$ M. Legenhausen, Pluralitas Dan Pluralisme Agama (Jakarta: Sadhra Press, 2010), 37.

${ }^{45}$ Kholili Hasib, Kritik Atas Konsep Abrahamic Faiths Dalam Studi Agama (Ponorogo: CIOS, 2010), 1.

${ }^{46}$ Nuriz, Problem Pluralisme Agama Dan Dampaknya Terhadap Kehidupan Sosial Keagamaan, 2.

47 Hamid Fahmy Zarkasyi, Liberalisasi Pemikiran Islam (Gerakan Bersama Missionaris, Orientalis Dan Kolonialis) (Ponorogo: CIOS, 2008), 20.

${ }^{48}$ Hamid Fahmy Zarkasyi, Misykat Refleksi Tentang Westernisasi, Liberalisasi Dan Islam, 9.

Tribakti: Jurnal Pemikiran Keislaman

Volume 32, Nomor 1, Januari 2021 
Dalam paham pluralisme agama terbagi atas dua besar teori, yakni ideologi global (global theology) ${ }^{49}$ dan kesatuan agama-agama (transcendent unity of religion). Dalam pemikiran Barat bersatunya semua agama di sebut dengan Transcendent Unity of Religion. Transcendent Unity of Religion (kesatuan agama-agama) adalah kesatuan yang melaupaui segala bentuk dan sosok lahiriyah, eksternal. ${ }^{50}$ Hal ini menyatakan bahwa Tuhan berada di titik puncak sementara semua agama (Hindu, Budha, Kristen, Yahudi, Konghucu, dan Islam) mengalir ke bawah dari titik puncak tersebut, begitu juga sebaliknya dalam waktu yang sama semua agama naik dari bawah ke atas dan saling berkaitan dan akhirnya bertemu pada puncak titik tersebut.

Sedangkan Al-Hallaj disebut memiliki konsep yang bernama Wahdah Al-Adyan. Wahdah Al-Adyan merupakan konsep tasawuf Al-Hallaj yang klaim sebagai pencetus pemikiran dalam pluralisme agama. Padahal jika dianalisis lebih mendalam konsep Wahdah Al-Adyan merupakan konsep yang disamakan oleh para orientalis dengan kosep Transcendent Unity of Religion. Dimana Transcendent Unity of Religion merupakancabang pemikiran dalam pluralisme agama.

Untuk membuktikan bahwa Jika dilihat dari segi etimologi kata Wahdat AlAdyan merupakan kata yang berasal dari bahasa Arab. Kata Wahdat bermakna kesatuan, kesamaan dan keesaan. ${ }^{51}$ Dan kata Adyan merupakan kata jamak yang berasal dari kata Din yang berarti agama. ${ }^{52}$ Konsep wahdat al-adyan dalam kajian sufi kini disandingkan dengan kajian pluralisme agama. Dimana banyak penulis artikel bahkan tesis menyakini bahwa wahdat al adyan memiliki arti yang sama dengan pluralisme agama, yang menyatakan bahwa semua agama itu secara dzahir memiliki perbedaan dari segi nama, prakter ritual dalam ibadah, namun secara hakikatnya semua agama itu berasal dari agama yang sama. ${ }^{53}$ Fatimah Utsman juga menambahkan bahwa wahdat al-Adyan menjelaskan bahwa pada hakikatnya agama-agama bertujuan sama dan mengabdi kepada Tuhan yang sama pula. Perbedaan yang ada hanya bentuk luar dan namanya saja. Jadi, agama apapun dapat dipahami setara karena sumbernya satu, yakni Tuhan. ${ }^{54}$

\footnotetext{
49 Jhon Hick, Philosophy of Religion (New Delhi: Prentice Hall, 1963), 112-213.

50 Anis Malik Thoha, Tren Pluralisme Agama (Jakarta: Gema Insani, 2007), 115.

${ }^{51}$ Rahmil Shaliba, “Al-Mu'jam Al-Falsafi” (Beirut: Dar al-Kitab al-Banani, 1973), 361.

${ }^{52}$ Fatimah Usman, "Wahdat Al-Adyan : Dialog Pluralisme Agama" (Yogyakarta: LKis, 2002), 12.

${ }^{53}$ Usman, 18. Lihat juga : Kautsar Azharai Noer, "Tasawuf Parenial, Kearifan Kritis Kaum Sufi" (Jakarta: PT. Serambi Ilmu Semesta, 2003), 36-38.

${ }^{54}$ Usman, "Wahdat Al-Adyan : Dialog Pluralisme Agama," 2.
} 
Jika dilihat dari definisi dan kajian secara teologi konsep Transcendent Unity of Religion (kesatuan agama-agama) dan wahdat al-Adyan memiliki persamaan dari segi makna yakni sama-sama mengarah kepada penyatuan Tuhan pada titik transendennya. Teori kesatuan transendensi agama merupakan usaha untuk mencari term universal yang dapat diterima oleh semua agama-agama di dunia.

Untuk memahami makna trensendent maka haruslah didahului dengan apa itu trensendent.Trensendent berasal dari bahasa Inggris dalam Webster's New International Dictionary of the English Language, "to trensendent berarti to go lie beyond the limits of experienc, knowledge (menuju atau berada diluar jangkauan pengalaman, ilmu); atau to escape inclusion in a category, classification, etc." (lepas dari cakupan kategori dl1). ${ }^{55}$ Kemudian dalam Oxford Dictionary and Thesaurus mendefinisikan makna trensendent dengan arti yang sama. To trensendent berarti "be beyond the range or grasp of human experience, reason, belief etc." Arti bebasnya; berada diluar tingkatan atau jangkauan pengalaman manusia, nalar, kepercayaan, dll). ${ }^{56}$

Dari definisi diatas dapat disimpulkan bahwa trensendent memiliki makna sesuatu yang diluar nalar manusia dan tidak terjangkau. Jika definisi ini dikaitan dengan pluralisme agama maka trensendent merujuk kepada kepada kekuatan supernatural atau suprarasional yang abstrak dan tidak bisa dijangkau oleh manusia baik dari indrawi maupun rasional. Sehingga hal ini mengarah kepada kekuatan Tuhan yang paling tinggi, mengatasi semua Tuhan-Tuhan yang ada dalam agama atau dengan arti lain semua agama bersatu dalam esoteris yang sama.

Oleh karena itu dapat dikatakan bahwa konsep wahdat al-adyan dan Transcendent Unity of Religion (kesatuan agama-agama) merupakan pemindahan bahasa dari bahasa inggris ke bahasa Arab, sehingga mampu menghasilkan asumsi bahwa wahdat al-adyan merupakan konsep yang berasal dari ajaran Islam. Dengan adanya asumsi ini maka pemahaman mengenai wahdat al-adyan (kesatuan agamaagama) lebih mudah di terima. Padahal jika dilihat dalam konsep metafisika yang ada dalam Islam memiliki perbedaan dengan konsep metafisikan yang dimiliki oleh Barat.Terutama dalam ranah teologi antara tasawuf dan pluralisme agama. Konsep metafisika dalam Islam bersumber dari wahyu dan bukan bersumber dari spekulatif filosofis para filosof ataupun tokoh agama yang berasal dari pengamatan data

55 Sara Tullouch, The Oxford Dictionary and Thhesaurus (Oxford: Oxford Univeristy, 1984), 1657.

${ }^{56}$ William Allan Anderson, Webster's New International Dictionary of The English Lang, 2nd ed. (Springfield: G \& C Merriam Publishers, 1957), 2698.

Tribakti: Jurnal Pemikiran Keislaman

Volume 32, Nomor 1, Januari 2021 
pengalaman indrawi. ${ }^{57}$ Dilihat dari pelaksaan kaum sufi terhadap praktek ajaran tasawuf, mereka akan tetap berpegang teguh dengan nilai-nilai yang terdapat dalam AlQur'an dan Sunnah Nabi Muhammad Saw. ${ }^{58}$

\section{Distorsi terhadap Syair Al-Hallaj}

Pemikiran al-Hallaj banyak tertuang dalam bait-bait syair yang ia tulis dalam bukunya. Salah satu pemikirannya tentang wahdatul Adyan dianggap sebagai pencetus pluralisme agama dalam Islam. Hal ini dikarenakan adanya syair al-Hallaj yang membahas mengenai agama:

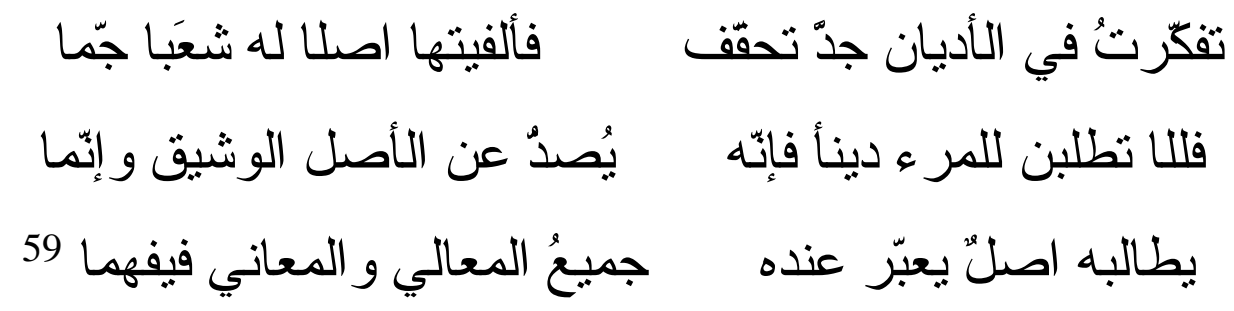

Syair diatas merupakan syair yang dilegitimasi sebagai pemikiran Al-Hallaj yang mengarah pada konsep wahdat al-Adyan dimana dalam arti bebasnya, syair ini memiliki arti:

Aku berfikir dengan sungguh-sungguh dalam masalah agama-agama,

Kemudian aku dapati satu pangkal yang mempunyai cabang-cabang yang banyak, janganlah engkau memaksakan satu agama kepada seseorang, karena itu akan memalingkan dari asal mula, hanya satu yang dapat ditanyakan padanya: Asal mula itu sendiri harus dicari, dia yang menyingkap semua kebesaran dan semua makna, baru manusia akan memahaminya.

Jika dianalisa lebih mendalam makna syair ini memberikan penjelasan tentang pengalaman individu tententu dengan agama-agama. Hal ini dapat dilihat dari sejarah perjalanan hidup al-Hallaj dari dia kecil. Sebab Al-Hallaj sudah mengalami pengalaman individu dengan agama-agama, hal ini bisa dilihat melalui silsilah keluarga besar $\mathrm{Al}$ hallaj mulai dari kakeknya Muhammad ialah seorang Zoroaster (Majusi), sedangkan ayahnya ialah seorang Muslim dan moyoritas keluarganya adalah Islam, namun Al-

${ }^{57}$ Adnin Arnas, "Wacana Metafisika Al-Attas," Jurnal Islamia Volume XI, No.2 (2017): 30. Lihat juga: Syed Naquib al- Attas, "Prolegomena to the Metaphysics of Islam," Kuala Lumpur: International Institute of Islamic Thought and Civilization, 1995, 1-2. 1988), 34.

58 Ali Ma'bad Fargholi, Al-Thasawwuf Baina Mu'ayyid Wa Mu'aridh (Beirut: Daru al-Kutub,

${ }^{59}$ Massignon, “LE DIWAN AL-Hallaj. Essay De Reconstitution,” 118. 
Hallaj masih memiliki beberapa orang keluarga yang beragama Kristen dan Yahudi. ${ }^{60}$ Ada logika yang terpotong

Jadi kesatuan agama (wahdat Al-Adyan) yang diklaim kalangan pluralis sebagai pluralisme agama tidak bisa disebut sebagai 'agama' namun hanya pengalaman keagamaan (religious experience). ${ }^{61}$ Sebab jika menelisik dalam sejarah juga dapat ditemukan bahwa oleh Al-Hallaj menulis tentang syair ini merupakan syair yang diperuntukan untuk berinteraksi antara umat beragama. Terbukti sejak abad ke tiga hingga ke empat hijriah dimana perhatain para sufi beralih dari diskursus jiwa menjadi ilmu moral keagamaan, baik dari aspek teoritis dan praktis dalam memperbaiki hubungan kepada Allah dan manusia. ${ }^{62}$

Dengan demikian klaim al-Hallaj sebagai bapak pluralisme agama hanya merupakan spekulasi para pluralis. Al-Hallaj tetap teguh dengan agamanya yakni Islam hingga akhir hayatnya.

\section{Kesimpulan}

Dari semua penjebaran di atas dapat disimpulkan bahwa kalangan pluralis mendekostruksi tasawuf Islam al-Hallaj.Tuduhan Al-Hallaj sebagai bapak pluralisme dalam Islam tidak dapat di buktikan secara nyata. Hal ini dikarenakan kesalahpahaman dan tidak komprehensif dalam memahami ungkapan al-Hallaj dalam bait-bait syairnya serta bertujuan untuk kepentingan liberalisasi dengan upaya interpretasi teks dan penyelewengan bahasa dari Transcendent Unity of Religion menjadi wahdat Al-Adyan.

Namun, dengan kajian ini dapat dilihat bahwa al-Hallaj sampai masa akhir hidupnya masih tetap berpegang teguh dengan keyakinan nilai-nilai Islam. Serta didukung dengan pendapat para sufi yang memberikan pujian terhadap pemikiran tasawuf al-Hallaj. Hal penting yang perlu di tekankan juga bahwa dalam Islam inti pengamalan terhadap agama adalah Tauhid. Kalimat syahdat atas pengakuan penerimaan Islam menegaskan bahwa "tidak ada Tuhan selain Allah.

Oleh karena itu konsep wahdat al-Adyan yang diklaim sebagai konsep pluralisme agama dalam Islam merupakan pemahaman yang keliru. Dalam Islam tidak ada yang namanya kesatuan agama (transendent of unity) atau wahdat al-Adyan. Yang

\footnotetext{
${ }^{60}$ Louis Massignon, The Passion of Al-Hallaj: Mystic and Martyr of Islam, Abridged E (Princeton University Press, n.d.), 48.

61 Arnas, "Wacana Metafisika Al-Attas," 34.

${ }^{62}$ Ahmad Tholabi Kharlie, "Pergumulan Pemikiran Mistik Filosofi Di Nusantara Abad 16-18 M," Jurnal Al-Qalam Vol. 23 No (n.d.): 2245.
}

Tribakti: Jurnal Pemikiran Keislaman

Volume 32, Nomor 1, Januari 2021 
ada ialah pengalaman al-Hallaj dalam memahami perbedaan beragama. Dengan demikian konsep wahdat al-Adyan merupakan klaim yang diusung oleh kalangan pluralis untuk membuka celah dalam kajian tasawuf yang dikaitan dengan pluralisme agama.

\section{Daftar Pustaka}

Al-A'sam, Abdul Amir. Al-Faylasuf Al-Ghazali, n.d.

Al-Ghazali, Abu Hamid. "Ihya Ulum Al-Din.” Kairo: Mushthafa al-Babi al-Halabi, 1939.

Al-Hallaj, Husain bin Manshur. Al-Thowasin. Edited by Terj.Kasyif Ghoiby. Yogyakarta: Titah Surga, 2009.

Al-Hallaj Sang Sufi Syahid. Yogykarta: Fajar Pustka Baru, 2000.

Al-Jailani, Syekh Abdul Qadir. Qalaid Al Jawahir, n.d.

Al-Sarraj, Abu Nasr. Al-Luma. Edited by Editor Abdul Halim Mahmud dan Thaha Abdul Baqi Suru. Kairo: Dar al-Kutub al-Haditsah, 1960.

Al, Kautsar Azhari Noer et. Warisan Agung Tasawuf: Mengenal Karya Besar Para Sufi. Jakarta: Sandra Press, 2015.

Anderson, William Allan. Webster's New International Dictionary of The English Lang. 2nd ed. Springfield: G \& C Merriam Publishers, 1957.

Arnas, Adnin. "Wacana Metafisika Al-Attas.” Jurnal Islamia Volume XI, (2017).

Fargholi, Ali Ma'bad. Al-Thasawwuf Baina Mu'ayyid Wa Mu'aridh. Beirut: Daru alKutub, 1988.

Hamdie, Ilham Masykuri. "Jejak-Jejak Pluralisme Agama Dalam Sufisme.” Khazanah: Jurnal Studi Islam Dan Humaniora 17, no. 2 (2019): 263. https://doi.org/10.18592/khazanah.v17i2.3207.

Hamid Fahmy Zarkasyi. Liberalisasi Pemikiran Islam (Gerakan Bersama Missionaris, Orientalis Dan Kolonialis). Ponorogo: CIOS, 2008.

—. Misykat Refleksi Tentang Westernisasi, Liberalisasi Dan Islam. Jakarta: INSISTS, 2012.

Hanik, Umi. "Pluralisme Agama Di Indonesia." Jurnal Pemikiran Keislaman 25, no. 1 (2014): 44-63. https://doi.org/10.33367/tribakti.v25i1.154.

Hasib, Kholili. Kritik Atas Konsep Abrahamic Faiths Dalam Studi Agama. Ponorogo: CIOS, 2010.

Hick, Jhon. Philosophy of Religion. New Delhi: Prentice Hall, 1963.

Hornby, A.S. Oxford Advanced Leaner's Dictionary of Corrent English Language. Cet.11. London: Oxford Univeristy Press, 1983. 
Ibrahim. Metodologi Penelitian Kualitatif. Bandung: ALFABETA, 2015.

Indonesia, Majelis Ulama. "Pluralisme, Liberalisme, Dan Sekularisme Agama." Himpunan Fatwa MUI, 2005.

Internasional Jurnal of Islamic Thought. "Martyrdom of Al-Hallaj and Unity of the Existence: The Condomners and the Commenders," n.d.

Kabbani, Syekh Muhammad Hisyam. Tasawuf Dan Ihsan "Antivirus Kebatilan Dan Kezaliman. Jakarta: PT. Serambi Ilmu Semesta, 2007.

Karomi, Kholid. "Penolakan Ibnu Arabi Terhadap Pluralisme Agama." Kalimah 12, no. 1 (2014): 49. https://doi.org/10.21111/klm.v12i1.218.

Kartanegara, Mulyadi. "Eksekusi Al-Hallaj: Persoalan Teologi Atau Konspirasi Politik?" Dalam Sekapur Sirih Dalam Buku Gilani Kamran, Ana Al-Haqq (Akulah Kebenaran): Menyingkap Teosofi Al-Hallaj Dalam Kitab Thawasin. Edited by Terj. Wahyudi. Surabaya: Risalah Gusti, n.d.

Khalkan, Ibnu. Wafayat Al-A'yaan. Juz I. Boolaq, n.d.

Kharlie, Ahmad Tholabi. "Pergumulan Pemikiran Mistik Filosofi Di Nusantara Abad 16-18 M.” Jurnal Al-Qalam Vol. 23 No (n.d.).

Khuluq, Lathiful. The Notion of Love of God in Al Hallaj Dalam the Dynamic of Islamic Civilization. Yogyakarta: Titian Press, n.d.

Legenhausen, M. Pluralitas Dan Pluralisme Agama. Jakarta: Sadhra Press, 2010.

Mahmud, Abd al-Halim. Al-Risalah Al-Qusyairiyah. Kairo: Muassasah Dar al-Sya'b, 1989.

Manshur, Syeikh Husain, Hussain Manshur Al-hallaj, and Muhammad Saw. "At Thowasin Al Azal," n.d.

Mason, Herbert W. Al-Hallaj. London: Curzon Press, 1995.

Massignon, Louis. A History of Muslim Philosophy. Wiesbaden: Otto Harrassowitz, 1963.

. Al-Hallaj, Mystic and Martyr. Abridged Edition, Princeton Universitu Press, New Jersey, n.d.

—. "LE DIWAN AL-Hallaj. Essay De Reconstitution." Jurnal Asiatuque, no. Librairie Orinetaliste Paul Geuthner (1931).

- The Passion of Al-Hallaj: Mystic and Martyr of Islam. Abridged E. Princeton University Press, n.d.

MUI. "Fatwa MUI Tentang Pluralisme, Liberalisme Dan Sekularisme Agama," 1970, 98-100.

Nata, Abuddin. Metodologi Studi Islam. Jakarta: Raja Wali Press, 2013.

Nicholson, Reynold A. Al-Hallaj, Encyclopedia of Religion and Ethics. New York: Charles Scribners Son, tt, n.d.

Noer, Kautsar Azharai. “Tasawuf Parenial, Kearifan Kritis Kaum Sufi.” Jakarta: PT.

Tribakti: Jurnal Pemikiran Keislaman

Volume 32, Nomor 1, Januari 2021 
Serambi Ilmu Semesta, 2003.

Nuriz, Adib Fuadi. Problem Pluralisme Agama Dan Dampaknya Terhadap Kehidupan Sosial Keagamaan. Ponorogo: CIOS, 2015.

Rahardjo, Mudjia. Analisis Muatan Sebagai Metode Pengukuran Kata Pengantar Dalam Nanang Martono, "Metode Penelitian Kualitatif Analisis Isi Dan Analisis Data Sekunder. Jakarta: PT Raja Gravindo Persada, 2014.

Rizal Maulana, Abdullah Muslich. "Kesatuan Transenden Agama-Agama Dalam Perspektif Tasawuf (Kritik Atas Pemikiran Frithjof Schuon)." Kalimah 12, no. 2 (2014): 197. https://doi.org/10.21111/klm.v12i2.236.

Rumi, Jalaludin. Fihi Ma Fihi. Yogyakarta: FORUM, 2014.

Saebani, Beni Ahmad. Filsafat Ilmu Dan Metode Penelitian. Bandung: Pustaka Setia, 2015.

Sara Tullouch. The Oxford Dictionary and Thhesaurus. Oxford: Oxford Univeristy, 1984.

Shaliba, Rahmil. “Al-Mu’jam Al-Falsafi.” Beirut: Dar al-Kitab al-Banani, 1973.

Sholikhin, Muhammad. Filsafat Dan Metafisika Dalam Islam "Sebuah Penjelajahan Nalar Pengalaman Mistik Dan Perjalananan Aliean Manunggaling Kawula-Gusti. Yogyakarta: NARASI, 2008.

Siti Zulaiha. "Pendekatan Metodologis Dan Teologis Bagi Pengembangan Dan Peningkatan Kualitas Guru MI.” Ar-Riayah : Jurnal Pendidikan Dasar 1, no. 01 (2017): h. 45-64.

Slamet, Achmad. Buku Ajar Metodologi Studi Islam: (Kajian Metode Dalam Ilmu Keislaman). Yogyakarta: Deepublish, 2016.

Suryadilaga, M. Alfatih. Miftahus Sufi. Yogyakarta: Teras, 2018.

Syed Naquib al- Attas. "Prolegomena to the Metaphysics of Islam." Kuala Lumpur: International Institute of Islamic Thought and Civilization, 1995, 107.

Thoha, Anis Malik. Tren Pluralisme Agama. Jakarta: Gema Insani, 2007.

Usman, Fatimah. "Wahdat Al-Adyan : Dialog Pluralisme Agama." Yogyakarta: LKis, 2002.

Yunus, Firdaus M. "Agama Dan Pluralisme.” Jurnal Ilmiah Islam Futura 13, no. 2 (2014): 213. https://doi.org/10.22373/jiif.v13i2.72. 